Journal of Patient-Centered

\title{
Impact of the Heart WATCH Program on Patients at Risk of Developing Metabolic Syndrome, Prediabetes or Cardiovascular Disease
}

\author{
Jennifer T. Fink \\ Kathryn K. Havens \\ Julia A. Schumacher \\ Renee E. Walker \\ George L. Morris III \\ David A. Nelson \\ Maharaj Singh \\ Ron A. Cisler
}

Follow this and additional works at: https://aah.org/jpcrr

Part of the Cardiology Commons, Community Health and Preventive Medicine Commons, Endocrinology, Diabetes, and Metabolism Commons, Health Services Research Commons, and the Preventive Medicine Commons

\section{Recommended Citation}

Fink JT, Havens KK, Schumacher JA, Walker RE, Morris GL 3rd, Nelson DA, Singh M, Cisler RA. Impact of the Heart WATCH program on patients at risk of developing metabolic syndrome, prediabetes or cardiovascular disease. J Patient Cent Res Rev. 2015;2:56-63. doi: 10.17294/2330-0698.1035

Published quarterly by Midwest-based health system Advocate Aurora Health and indexed in PubMed Central, the Journal of Patient-Centered Research and Reviews (JPCRR) is an open access, peer-reviewed medical journal focused on disseminating scholarly works devoted to improving patient-centered care practices, health outcomes, and the patient experience. 


\title{
Impact of the Heart WATCH Program on Patients at Risk of Developing Metabolic Syndrome, Prediabetes or Cardiovascular Disease
}

\author{
Jennifer T. Fink, PhD, MS, ${ }^{1,2,3}$ Kathryn K. Havens, MD, ${ }^{4}$ Julia A. Schumacher, APNP, ${ }^{1}$ \\ Renee E. Walker, DrPH, ${ }^{2,5}$ George L. Morris, MD, ${ }^{1,2,5}$ David A. Nelson, PhD, MS, ${ }^{6}$ \\ Maharaj Singh, PhD, ${ }^{1}$ Ron A. Cisler, PhD, $\mathrm{MS}^{2,3,5,7}$ \\ ${ }^{1}$ Aurora Health Care, Milwaukee, WI \\ ${ }^{2}$ Center for Urban Population Health, Milwaukee, WI \\ ${ }^{3}$ Department of Health Informatics \& Administration, University of Wisconsin-Milwaukee, Milwaukee, WI \\ ${ }^{4}$ Clement J. Zablocki VA Medical Center, Milwaukee, WI \\ ${ }^{5} \mathrm{Joseph}$ J. Zilber School of Public Health, University of Wisconsin-Milwaukee, Milwaukee, WI \\ ${ }^{6}$ Department of Family and Community Medicine, Medical College of Wisconsin, Milwaukee, WI \\ ${ }^{7}$ Department of Population Health Sciences, University of Wisconsin School of Medicine and Public Health, Madison, WI
}

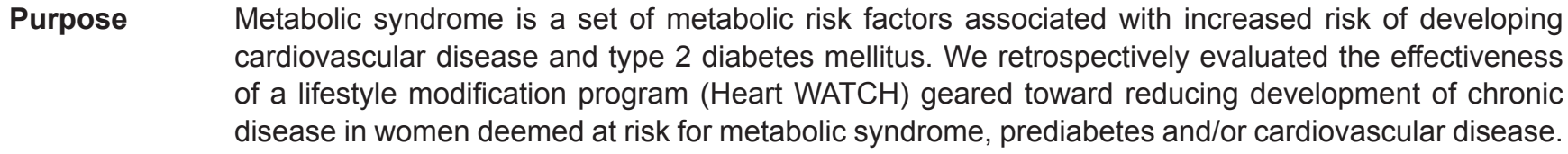

Methods Our institution's Heart WATCH program consists of screening sessions with a multidisciplinary team (physician/nurse, nutritionist and psychologist), a minimum of three visits with a nurse practitioner and weekly follow-up phone calls for a 14-week period. Sociodemographic variables were obtained at initial visit. Biometric testing indices and self-reported clinical and behavioral health measures were recorded pre- and postintervention, and compared using paired $t$-tests or McNemar's test as appropriate.

Results Heart WATCH enrolled 242 women from November 2006 to April 2014, and $193(80 \%)$ completed all phases of the 14-week lifestyle intervention. Postintervention, participants demonstrated improved health status in all areas and improved significantly in the following areas: diet/nutrition $(P=0.014)$, exercise $(P<0.001)$, stress $(P<0.0001)$, quality of life $(P=0.003)$, weight $(P<0.0001)$, waist circumference $(P=0.01)$ and total cholesterol $(P=0.019)$. Clinically meaningful improvements were realized by participants who moved to a healthier classification in a number of vital signs and blood panel indices.

Conclusions These findings suggest the "elevated risk profile" for women with components of metabolic syndrome can be reversed through a lifestyle program focused on reducing risk factors associated with cardiovascular disease and prediabetes. Future research is needed to determine mechanisms of risk reduction as well as optimal patient-centered and culturally appropriate approaches to weight management. (J Patient-Centered Res Rev. 2015;2:56-63.)

Keywords metabolic syndrome, diabetes, cardiovascular disease, women, weight loss intervention, multidisciplinary team

Metabolic syndrome (MetS) is a constellation of metabolic risk factors that are associated with increased risk of developing cardiovascular disease and type

Correspondence: Jennifer T. Fink, PhD, 2400 E. Hartford

Avenue, MW Quadrant Building B, Room \#6455,

Milwaukee, WI, 53201, T: 262-323-9393, Email:

jennifer.fink@aurora.org
2 diabetes mellitus. ${ }^{1-3}$ It is estimated that individuals with MetS are 2-2.5 times more likely to develop cardiovascular disease compared to those without the syndrome. ${ }^{3}$ The predominant risk factors that make up MetS are abdominal obesity (i.e. waist circumference of $\geq 35$ inches in women and $\geq 40$ inches in men or body mass index $\left.[\mathrm{BMI}] \geq 30 \mathrm{~kg} / \mathrm{m}^{2}\right)^{4-6}$ and insulin resistance. ${ }^{5,7}$ Both of these adverse outcomes frequently result from physical inactivity ${ }^{6}$ and a high-fat, high- 
cholesterol diet. ${ }^{8}$ Other risk factors for MetS include raised triglycerides $(>150 \mathrm{mg} / \mathrm{dL}$ [or $1.7 \mathrm{mmol} / \mathrm{L}]$ ) or specific treatment for this lipid abnormality, reduced high-density lipoprotein (HDL) cholesterol $(<40 \mathrm{mg} / \mathrm{dL}$ [or $1.03 \mathrm{mmol} / \mathrm{L}$ ] in men and $<50 \mathrm{mg} / \mathrm{dL}$ [or $1.29 \mathrm{mmol} / \mathrm{L}$ ] in women) or specific treatment for this lipid abnormality, raised blood pressure (systolic $>130 \mathrm{mmHg}$ or diastolic $>85 \mathrm{mmHg}$ ) or treatment of previously diagnosed hypertension, raised fasting plasma glucose (> $100 \mathrm{mg} / \mathrm{dL}$ [or $5.6 \mathrm{mmol} / \mathrm{L}])$ or previously diagnosed type 2 diabetes. ${ }^{1,5,9}$

Several diagnostic criteria for MetS have been proposed, including benchmarks from the World Health Organization (WHO), the European Group for Study of Insulin Resistance (EGIR), the National Cholesterol Education Program Adult Treatment Panel III (ATP III), the American Association of Clinical Endocrinologists (AACE) and the International Diabetes Foundation (IDF). ${ }^{1-3,10}$ Differences in these diagnoses reflect an addition or exclusion of a specific criterion. For example, insulin resistance is a clinical measure for diagnosing MetS in WHO, EGIR and AACE criteria, but not in the criteria proposed by ATP III or IDF. ${ }^{1}$ As a result of the varying criteria, the reported prevalence of MetS varies greatly. Findings from a meta-analysis conducted by Galassi and colleagues examining the association between MetS and cardiovascular disease in prospective studies reported the prevalence of MetS ranged from $38 \%$ to $77 \%$ when using ATP III and WHO classifications, respectively. ${ }^{10}$

According to findings from the National Health and Nutrition Examination Survey 2003-2006, which used the ATP III diagnostic criteria, the age-adjusted prevalence of MetS in adults was 34\%. Differences in MetS prevalence were observed by age, sex and BMI. ${ }^{5}$ Specifically, each progressive 20-year age group resulted in an increased prevalence of MetS in both men and women. For example, women age $\geq 60$ years were more than six times as likely to meet the criteria for MetS compared with women 20-39 years of age. ${ }^{5}$ In addition, prevalence increased as mean BMI increased. Compared to normal weight and underweight women, overweight and obese women were approximately 5.5 and 17 times more likely to have MetS, respectively. ${ }^{5}$
Specific guidelines for treating MetS remain unclear. The Heart WATCH (Women Acting To Create Heart Health) program at our primary institution is based on diabetes prevention recommendations and receives reimbursement from patient health insurance for the diagnosis of metabolic syndrome and cardiovascular risk factors. Patients were referred to the program by their physicians and were accepted into the program if they had at least one MetS risk factor. Our Heart WATCH program defines MetS using the IDF criteria. This definition includes abdominal obesity plus two of the following: elevated triglycerides, reduced HDL cholesterol, elevated blood pressure or elevated fasting plasma glucose.

The purpose of this study was to evaluate the impact of Heart WATCH as a lifestyle modification program geared toward reducing the risk of chronic disease developing in women who have MetS, prediabetes and cardiovascular disease risk factors. Regarding the outcomes identified in this manuscript, two primary questions were asked. 1) Was there significant weight loss related to participation in Heart WATCH? 2) Are there statistically significant and clinically meaningful improvements in MetS risk factors and health status indictors related to participation in the Heart WATCH program?

\section{METHODS \\ Study Design}

We performed a retrospective evaluation of program effectiveness using evidence-based quality improvement measures and data collected as part of the Heart WATCH program. Women were asked to provide information before and after program intervention as part of a quality improvement assessment of the program. The investigative team received approval for accessing available patient data from the local institutional review board in December 2013 (Protocol \#13-137MR). Heart WATCH enrolled eligible women who presented to our health system's hospitals and clinics beginning in November 2006 and through April 2014.

\section{Heart WATCH Program Overview}

The Heart WATCH program is implemented over a 14-week period. The first two visits, which occur over the first two weeks, make up the screening process. Intervention begins following confirmation of the enrolled woman screening positive for at least one MetS, prediabetes or cardiovascular risk factor. The 
intervention portion of Heart WATCH consists of a 12-week lifestyle modification program, and includes a minimum of three visits along with weekly phone calls. The visit schedule is described in detail in Table 1.

\section{Measures}

A number of measures were assessed in this program, including sociodemographics, biometric testing indices and self-reported clinical and behavioral health measures. Sociodemographic variables were collected at the initial screening visit and included age, gender (all female) and zip code. Patients were asked to complete self-reporting clinical and behavioral health scales at the initial screening visit and then again at the final intervention visit. These measures included patient-reported processes designed for Heart WATCH: an 8-item diet survey (potential range 0-24), a 5-item exercise survey (potential range 1-18) and a 3-item quality-of-life survey (potential range 0-30). The diet, exercise and quality-of-life surveys were compiled by the program's medical professionals. In addition, two standardized measures were administered, the 10- item (potential range 0-40) Perceived Stress Scale (PSS-10) ${ }^{11}$ and the 9-item Patient Health Questionnaire (PHQ-9). ${ }^{12}$ All biometrics, including height, weight, BMI, blood pressure, heart rate, hip circumference, waist circumference and body fat percentage, were completed at the initial screening visit and again at the final intervention visit. Measures were available for women differentially depending on when measures were fully incorporated into the preintervention baseline and the follow-up assessment protocol.

\section{Data Availability and Analyses}

Because this was a retrospective evaluation of a clinicbased program, data was not collected systematically and therefore was inconsistently available. Paired $t$-tests were used to determine if patient scores from pre- to postintervention were statistically different. We assumed equal variances for these intraparticipant analyses because participants served as their own control and changes were expected for some but not all participants. For the purpose of study analyses, U.S. standard measurement units were used for all blood panel biomarker data. Statistical analyses were

Table 1. Heart WATCH program description

\begin{tabular}{|c|c|}
\hline Visit number & Visit description \\
\hline Screening Visit \#1 & $\begin{array}{l}\text { Screening visit for cardiovascular disease risk factors. Visit includes biometric screening for } \\
\text { height, weight, blood pressure and heart rate; measurement of hip and waist circumference, } \\
\text { body mass index and body fat percentage; a physical examination; laboratory evaluations; and } \\
\text { a stress survey (PSS-10). Review of health history includes allergies, medications, surgeries, } \\
\text { hospitalizations and health condition. }\end{array}$ \\
\hline Screening Visit \#2 & $\begin{array}{l}\text { Visit includes discussion of the initial visit (Screening Visit \#1) findings, with a focus on each } \\
\text { patient's individual cardiovascular disease risk factors and proposed treatment plan. }\end{array}$ \\
\hline Week \#1 & $\begin{array}{l}\text { This 3-hour visit consists of a 45-minute visit with a dietician, a 45-minute visit with an exercise } \\
\text { therapist, } 30 \text { minutes with a nurse practitioner (NP), and } 45 \text { minutes with a behavioral health } \\
\text { specialist. Individualized plans for diet, exercise and stress control are developed and reviewed } \\
\text { with each patient. Patients receive resources to assist in meeting goals for diet and exercise, } \\
\text { including a food and exercise diary to monitor daily activities. }\end{array}$ \\
\hline Weeks \#2 - \#5 & $\begin{array}{l}\text { Weekly phone calls from registered nurse }(\mathrm{RN}) \text { coordinator are conducted to assist with any } \\
\text { concerns or questions, and to monitor diet, exercise and weight. Blood glucose and blood } \\
\text { pressure are measured if applicable. }\end{array}$ \\
\hline Week \#6 & $\begin{array}{l}\text { A 1-hour visit with the NP. Hip and waist circumference, body mass index and body fat } \\
\text { percentage are measured, and the patient's food and exercise diary is reviewed. }\end{array}$ \\
\hline Weeks \#7 - \#11 & $\begin{array}{l}\text { Weekly phone calls from RN coordinator to assist with any concerns, and to monitor diet, } \\
\text { exercise and weight. Blood glucose and blood pressure are measured if applicable. }\end{array}$ \\
\hline Week \#12 & $\begin{array}{l}\text { An in-person visit with the NP. Laboratory assessments are repeated. Physical evaluation } \\
\text { includes height, weight, blood pressure, heart rate, hip, waist, body mass index and body fat. } \\
\text { A detailed discussion of overall results, including lab tests, medications and changes in lifestyle, } \\
\text { is conducted. }\end{array}$ \\
\hline
\end{tabular}


performed using SAS version 9.2 (SAS Institute Inc., Cary, NC). In addition, for each of the eight biometric measures in which universal cut-offs were available, we determined the number and percentage of patients achieving one of three clinical status outcomes postintervention: 1) Good = maintained normal status or improved; 2) Borderline = suboptimal status with no change; or 3) Poor = remained impaired or worsened. Finally, we determined the total number of the five MetS-defining factors present for each patient both before and after Heart WATCH treatment. In this final subanalysis, we expected a small sample size due to the low number of patients who would have data available on all five indicators; however, removing cases without data for all five indicators was essential to avoid erroneously counting patients as not having MetS due to lack of viable data rather than truly scoring below criterion thresholds.

\section{RESULTS}

A total of 242 women signed up for the program over the study period. Of those initially enrolled patients, 193 (80\%) completed all phases of the program and made up the study population. Ages in this group ranged from 27 to 90 years (mean age was 54 years). Racial make-up was 75\% Caucasian, 16\% African American and $9 \%$ unknown. About $21 \%$ of the women resided within one of Milwaukee's 10 inner city zip codes, which annually experience the greatest degree of social and health inequities. ${ }^{13}$

Table 2 displays the change in self-reported clinical and behavioral health status indicators for program participants pre- and postintervention. On average, participants showed improvement in all clinical and behavioral health status measures after completion of the program. As shown, participants improved significantly from pre- to postintervention on their reports of diet/nutrition, exercise, stress, general health and quality of life.

Table 3 displays the change in vital sign and blood panel health status indicators for participants preand postintervention. On average, participants improved significantly from pre- to postintervention in weight and waist circumference. There was a small postintervention increase in mean BMI, but this increase was not statistically significant. Participants showed improvement in all blood panel health status measures after completion of the program. Improvements in mean total cholesterol, mean triglycerides and mean glucose were statistically significant. Slight improvements in systolic blood pressure, diastolic blood pressure, HDL cholesterol and low-density lipoprotein (LDL) cholesterol were not statistically significant.

Table 4 provides a breakdown of the number and percentage of patients achieving a "Good," "Borderline" or "Poor" clinical status outcome postintervention. Only $8 \%$ of patients achieved a normal BMI after completing the program. However, far more patients achieved a Good outcome on the other biometric measures: $61 \%$ had optimal LDL cholesterol, 59\% had desirable total cholesterol, 59\% had normal glucose level, 56\% had normal diastolic blood pressure, 51\% had normal triglycerides, $32 \%$ had normal systolic blood pressure,

Table 2. Self-reported clinical and behavioral health status of Heart WATCH participants pre- and postintervention

\begin{tabular}{|c|c|c|c|c|c|c|}
\hline \multirow[b]{2}{*}{ Outcome variable } & \multicolumn{2}{|c|}{ Preintervention } & \multicolumn{2}{|c|}{ Postintervention } & \multirow[b]{2}{*}{$t$} & \multirow[b]{2}{*}{$P$} \\
\hline & Mean & SD & Mean & SD & & \\
\hline Diet/nutrition, $\mathrm{n}=45$ & 11.27 & 2.73 & 18.49 & 3.20 & -2.57 & 0.014 \\
\hline Exercise, $\mathrm{n}=48$ & 4.50 & 3.26 & 8.19 & 4.09 & -5.90 & $<0.0001$ \\
\hline Stress (via PSS-10 questionnaire), $n=142$ & 16.05 & 7.51 & 13.11 & 6.99 & 5.80 & $<0.0001$ \\
\hline Health (via PHQ-9 questionnaire), $n=141$ & 7.34 & 5.58 & 4.41 & 4.18 & 7.13 & $<0.0001$ \\
\hline Quality of life, $n=44$ & 18.22 & 4.80 & 20.05 & 5.02 & -3.20 & 0.003 \\
\hline
\end{tabular}

SD, standard deviation. 
Table 3. Mean change in physical health status of Heart WATCH participants pre- and postintervention

\begin{tabular}{|c|c|c|c|c|c|c|}
\hline \multirow[b]{2}{*}{ Outcome variable } & \multicolumn{2}{|c|}{ Preintervention } & \multicolumn{2}{|c|}{ Postintervention } & \multirow[b]{2}{*}{$t$} & \multirow[b]{2}{*}{$P$} \\
\hline & Mean & SD & Mean & SD & & \\
\hline Body mass index, $n=62$ & 38.51 & 10.80 & 37.86 & 9.18 & 1.20 & 0.236 \\
\hline Weight, $n=64$ & 229.94 & 47.22 & 224.54 & 46.68 & 6.38 & $<0.0001$ \\
\hline Waist circumference, $n=64$ & 43.90 & 5.86 & 43.23 & 6.04 & 2.53 & 0.014 \\
\hline Systolic blood pressure, $n=84$ & 126.74 & 18.18 & 126.54 & 16.75 & 0.12 & 0.90 \\
\hline Diastolic blood pressure, $n=84$ & 75.52 & 10.85 & 76.07 & 9.60 & -0.53 & 0.59 \\
\hline Total cholesterol, $\mathrm{n}=46$ & 204.39 & 36.58 & 187.63 & 33.14 & 2.44 & 0.019 \\
\hline LDL cholesterol, $n=46$ & 125.32 & 34.88 & 113.10 & 32.92 & 1.99 & 0.052 \\
\hline HDL cholesterol, $n=41$ & 45.58 & 10.18 & 46.02 & 12.94 & -0.29 & 0.077 \\
\hline Triglycerides, $n=45$ & 181.93 & 80.47 & 154.87 & 64.05 & 2.84 & 0.007 \\
\hline Glucose, $n=63$ & 111.22 & 43.37 & 106.14 & 36.68 & 2.02 & 0.048 \\
\hline
\end{tabular}

$H D L$, high-density lipoprotein; $L D L$, low-density lipoprotein; SD, standard deviation.

Table 4. Postintervention clinical outcome status of biometric indicators of Heart WATCH participants

\begin{tabular}{lccc}
\hline & \multicolumn{3}{c}{ Clinical outcome status } \\
\cline { 2 - 4 } Biometric indicator & $\begin{array}{c}1=\text { Good } \\
\text { (maintained normal } \\
\text { status or improved) }\end{array}$ & $\begin{array}{c}\text { 2 = Borderline } \\
\text { (suboptimal status } \\
\text { and no change) }\end{array}$ & $\begin{array}{c}\text { 3 = Poor } \\
\text { (remained impaired } \\
\text { or worsened) }\end{array}$ \\
\hline Body mass index, $\mathrm{n}=62$ & $5(8 \%)$ & $7(11 \%)$ & $50(81 \%)$ \\
Systolic blood pressure, $\mathrm{n}=84$ & $27(32 \%)$ & $40(48 \%)$ & $17(20 \%)$ \\
Diastolic blood pressure, $\mathrm{n}=84$ & $47(56 \%)$ & $29(34 \%)$ & $8(10 \%)$ \\
Total cholesterol, $\mathrm{n}=46$ & $27(59 \%)$ & $18(39 \%)$ & $1(2 \%)$ \\
LDL cholesterol, $\mathrm{n}=46$ & $28(61 \%)$ & $15(33 \%)$ & $3(6 \%)$ \\
HDL cholesterol, $\mathrm{n}=41$ & $7(17 \%)$ & $22(54 \%)$ & $12(29 \%)$ \\
Triglycerides, $\mathrm{n}=45$ & $23(51 \%)$ & $11(24 \%)$ & $11(25 \%)$ \\
Glucose, $\mathrm{n}=63$ & $37(59 \%)$ & $16(25 \%)$ & $10(16 \%)$ \\
\hline
\end{tabular}

$H D L$, high-density lipoprotein; $L D L$, low-density lipoprotein.

and $17 \%$ had protective levels of HDL cholesterol. Although fully $81 \%$ were obese or morbidly obese after intervention, a far less proportion registered a Poor outcome on the other biometric measures: $2 \%$ had high total cholesterol, $6 \%$ had high LDL, $10 \%$ had high or very high diastolic blood pressure, $16 \%$ had glucose levels signifying diabetes, $20 \%$ had high or very high systolic blood pressure, $25 \%$ had high or very high triglycerides, and $29 \%$ had low (i.e. risky) HDL.

Of the 193 patients who completed the Heart WATCH program, we were able to retrospectively obtain all data points needed to determine presence or absence of MetS both before and after the intervention on 27. Of these 27, 8 did not have MetS pre-Heart WATCH and 19 did. Post-Heart WATCH, 11 of these 27 patients did not have MetS while 16 did. Although this change was not significant statistically $(\mathrm{S}=1.8, \mathrm{P}=0.375)$, we felt it important to note that three fewer patients had MetS postintervention.

\section{DISCUSSION}

To address MetS by risk factor mitigation, emphasis is often placed on lifestyle and behavioral changes such as 
increasing the amount and intensity of physical activity, modifying diet and attempting to reduce weight. ${ }^{1}$ It has been documented that higher aerobic capacity and self-reported physical activity are inversely associated with metabolic disorders and related conditions like cardiovascular disease mortality, impaired glucose tolerance and type 2 diabetes. ${ }^{14-19}$ Similarly, engaging in physical activity predicts MetS incidence in a dose-response manner. For instance, engaging in low levels of physical activity was shown to increase the incidence of MetS, whereas higher levels of physical activity were associated with lower MetS incidence. ${ }^{18,19}$ A study by Ford et al. showed nearly twofold odds of developing MetS among adults who did not engage in moderate or vigorous physical activity compared to their physically active counterparts (defined as at least 150 minutes of activity per week). ${ }^{20}$ Similar behavioral programs geared toward weight reduction by focusing on diet have been explored, ${ }^{21}$ given the salience and potential for modifying dietary practices.

The benefits of weight reduction are numerous and include improving all components of MetS. Specifically, weight loss has been found to treat adiposity, dyslipidemia, hypertension, insulin resistance and hyperglycemia. ${ }^{22}$ Even small reductions in weight have been shown to improve MetS risk factors, and it is speculated that a $5-10 \%$ loss of initial body weight can reduce triglycerides, increase HDL cholesterol, and decrease fasting blood glucose, insulin and hemoglobin A1c levels. ${ }^{23,24}$ One successful example is the Finnish Diabetes Prevention Study, which showed that, compared to the control group, the prevalence of MetS was reduced among participants who had modest weight reductions resulting from a lifestyle intervention. ${ }^{21}$ Another successful example of a behavioral intervention is the HERITAGE Family Study, which examined the impact of regular exercise to treat MetS, cardiovascular disease and type 2 diabetes in men and women. ${ }^{2}$ In the program, participants engaged in a 20 -week aerobic exercise regimen involving three sessions per week for a duration of 30-50 minutes at varying intensities. Results from this study showed that MetS risk factors decreased as a result of the exercise training program. In addition, $30 \%$ of the participants who met the criteria for MetS diagnosis at baseline no longer met the criteria upon completion of the intervention. ${ }^{2}$
Recommendations for change from existing studies focus either on the provider or the patient. For health care providers, additional education and training is recommended since health care providers care for patients with MetS. ${ }^{9}$ For patients, comprehensive programs geared toward addressing physical activity ${ }^{2}$ and proper diet/nutrition have been recommended. ${ }^{9}$ Investigations in which primary care providers provide counseling about diet and exercise have led to weight loss of $2.5 \mathrm{~kg}$ or less in studies with timeframes ranging from 6 to 18 months. ${ }^{2,9}$ Inadequate treatment contact may be responsible for such a small amount of weight loss. Given the requirements on providers' time, an increase in the frequency of provider-based obesity counseling does not appear to be a practical solution.

Specific guidelines for treating MetS are unclear. Additional gaps in the literature exist regarding best practices for lifestyle and behavioral modification interventions to address MetS within specific populations, including older adults and retirees and within targeted locations like workplaces..$^{25}$ Despite the increasing evidence of the benefits of lifestyle and behavioral interventions for increasing physical activity and improving diet, long-term adherence to either modification remains poor. However, based on existing literature, it is our opinion that behavioral and lifestyle approaches for reducing MetS and cardiovascular risk factors are the best evidence-based strategies to date given the improvements, albeit modest, these strategies provide in all components of MetS.

Based on recommendations from the literature on areas for future research, it appears there is a need to develop, implement and evaluate interventions that use a "patient-centered approach" whereby patients become engaged and involved based on their interests and what is available to them within their community. Given the modifiable nature of these risk factors, it appears a study that considers patient preferences would have strong potential to impact health through lifestyle modifications geared toward reducing the risk of MetS, prediabetes and cardiovascular disease. Relatedly, our findings have implications for reducing the risk factors associated with MetS, which could decrease the high rates of cardiovascular mortality experienced by women. The public health and clinical significance of this study is in the identification of strategies for early detection and 
treatment of MetS and prevention of prediabetes and cardiovascular disease.

The novel intervention of the Heart WATCH program is its patient-centered multidisciplinary approach to improving women's health. Participants entered into a 14-week program to mitigate the risk factors associated with MetS, prediabetes and cardiovascular disease. This program takes into account patient preferences and makes an impact on women's health through lifestyle modification and risk reduction. This multidisciplinary program proved to improve self-reported measures of diet/nutrition, exercise, general health and quality of life. Biometric measures of weight, waist circumference, cholesterol and triglycerides also improved. Improvements in BMI and LDL cholesterol were found but were not significant statistically. Individual patient change from before to after program intervention revealed that even though many women were still obese or morbidly obese, their clinical outcome status improved over the course of treatment. Finally, three participants who initially met the diagnostic definition of MetS no longer did after completion of the Heart WATCH intervention. Understanding how individual improvements on biometric measures can lead to an overall lowering of diabetes and cardiovascular risk, not only in the short term but over a more extended follow-up period, is an important focus for program design and evaluation.

Patients who meet criteria for MetS constitute a group experiencing an "elevated risk" for chronic health conditions. These patients have an opportunity for secondary prevention of additional severe morbidities such as type 2 diabetes mellitus and coronary vascular disease. Interventions similar to Heart WATCH have previously demonstrated the ability to reduce the risk factors that diagnose a patient with MetS. ${ }^{26}$ The economic benefit of preventing these conditions from developing has been shown to decrease long-term health costs. ${ }^{27}$ The U.S. Preventive Services Task Force's Guide to Clinical Preventive Services defines "secondary prevention measures" as those provided to individuals to prevent the onset of a targeted condition. ${ }^{28}$ Though diagnostic billing codes exist for MetS, it is important to recognize that none of the individual component risk factors that make up MetS, when taken separately, meet the criteria for a disease diagnosis. Through the Heart WATCH program, we attempted to identify women with elevated risk profiles but who were as-yet preclinical for diagnosable diabetes and cardiovascular problems, and provide an intervention to help prevent these diseases from manifesting.

Given the retrospective nature of our study, we are limited in making causal inferences. Another limitation is that some data were self-reported, which could suffer from participant reporting bias; however, laboratory biometrics also were reported as a more objective assessment of patient health status. Participants were a self-selected group of patients seeking help for weight management. Because patients entered into Heart WATCH over several years, factors such as time of year, economy, employment and other possible unrecognized factors were not controlled. In addition, we did not incorporate a comparison group to demonstrate that Heart WATCH participants changed differentially than a comparably matched group of nonparticipants. Still, present evaluation of the Heart WATCH program does provide guidance for the design of future interventions, including a systematic assessment that might resolve some of this study's limitations.

\section{CONCLUSIONS}

This study assessed the impact of a lifestyle modification program geared toward reducing the risk of chronic health conditions for women with components of metabolic syndrome. Preliminary results of this program are encouraging and warrant further study. There remains a need to better understand metabolic syndrome and its impact on women's health. Patient-centered and culturally appropriate approaches to weight loss hold tremendous promise and merit further investigation.

\section{Patient-Friendly Recap}

- Certain health conditions - including high blood pressure, insulin resistance, high blood sugar, abnormal cholesterol levels and excess body fat at the waist - are known to increase risk of heart disease, stroke and diabetes.

- Metabolic syndrome is a term used to describe the presence of several of these risk factors.

- The authors found that patients at risk for metabolic syndrome can improve their conditional status by participating in a 14-week clinically managed lifestyle program. 


\section{Conflicts of Interest}

None.

\section{REFERENCES}

1. Grundy SM, Cleeman JI, Daniels SR, et al. Diagnosis and management of the metabolic syndrome: an American Heart Association/National Heart, Lung, and Blood Institute scientific statement: Executive Summary. Crit Pathw Cardiol. 2005;4:198-203.

2. Katzmarzyk PT, Leon AS, Wilmore JH, et al. Targeting the metabolic syndrome with exercise: evidence from the HERITAGE Family Study. Med Sci Sports Exerc. 2003;35:1703-9. CrossRef

3. McNeill AM, Rosamond WD, Girman CJ, et al. The metabolic syndrome and 11-year risk of incident cardiovascular disease in the atherosclerosis risk in communities study. Diabetes Care. 2005;28:385-90. CrossRef

4. Carr DB, Utzschneider KM, Hull RL, et al. Intra-abdominal fat is a major determinant of the National Cholesterol Education Program Adult Treatment Panel III criteria for the metabolic syndrome. Diabetes. 2004;53:2087-94. CrossRef

5. Ervin RB. Prevalence of metabolic syndrome among adults 20 years of age and over, by sex, age, race and ethnicity, and body mass index: United States, 2003-2006. Natl Health Stat Report. 2009;(13):1-7.

6. Park YW, Zhu S, Palaniappan L, Heshka S, Carnethon MR, Heymsfield SB. The metabolic syndrome: prevalence and associated risk factor findings in the US population from the Third National Health and Nutrition Examination Survey, 1988-1994. Arch Intern Med. 2003;163:427-36. CrossRef

7. Ferrannini E, Haffner SM, Mitchell BD, Stern MP. Hyperinsulinaemia: the key feature of a cardiovascular and metabolic syndrome. Diabetologia. 1991;34:416-22. $\underline{\text { CrossRef }}$

8. National Cholesterol Education Program (NCEP) Expert Panel on Detection, Evaluation, and Treatment of High Blood Cholesterol in Adults (Adult Treatment Panel III). Third Report of the National Cholesterol Education Program (NCEP) Expert Panel on Detection, Evaluation, and Treatment of High Blood Cholesterol in Adults (Adult Treatment Panel III) final report. Circulation. 2002;106:3143-421.

9. Ford ES, Giles WH, Dietz WH. Prevalence of the metabolic syndrome among US adults: findings from the third National Health and Nutrition Examination Survey. JAMA. 2002;287:356-9. CrossRef

10. Galassi A, Reynolds K, He J. Metabolic syndrome and risk of cardiovascular disease: a meta-analysis. Am J Med. 2006;119:812-9. CrossRef

11. Katsarou A, Panagiotakos D, Zafeiropoulou A, et al. Validation of a Greek version of PSS-14; a global measure of perceived stress. Cent Eur J Public Health. 2012;20:104-9.

12. Spitzer RL, Kroenke K, Williams JB. Validation and utility of a self-report version of PRIME-MD: the PHQ primary care study. Primary Care Evaluation of Mental Disorders. Patient Health Questionnaire. JAMA. 1999;282:1737-44. CrossRef

13. Vila PM, Swain GR, Baumgardner DJ, Halsmer SE, Remington PL, Cisler RA. Health disparities in Milwaukee by socioeconomic status. WMJ. 2007;106:366-72.
14. Luke A, Dugas LR, Durazo-Arvizu RA, Cao G, Cooper RS. Assessing physical activity and its relationship to cardiovascular risk factors: NHANES 2003-2006. BMC Public Health. 2011;11:387. CrossRef

15. Ardern CI, Katzmarzyk PT, Janssen I, Church TS, Blair SN. Revised Adult Treatment Panel III guidelines and cardiovascular disease mortality in men attending a preventive medical clinic. Circulation. 2005;112:1478-85. CrossRef

16. Wei M, Gibbons LW, Kampert JB, Nichaman MZ, Blair SN. Low cardiorespiratory fitness and physical inactivity as predictors of mortality in men with type 2 diabetes. Ann Intern Med. 2000;132:605-11. CrossRef

17. Oguma Y, Shinoda-Tagawa T. Physical activity decreases cardiovascular disease risk in women: review and metaanalysis. Am J Prev Med. 2004;26:407-18. CrossRef

18. Laaksonen DE, Lakka HM, Salonen JT, Niskanen LK, Rauramaa R, Lakka TA. Low levels of leisure-time physical activity and cardiorespiratory fitness predict development of the metabolic syndrome. Diabetes Care. 2002; 25:1612-8. CrossRef

19. Ekelund U, Brage S, Franks PW, Hennings S, Emms S, Wareham NJ. Physical activity energy expenditure predicts progression toward the metabolic syndrome independently of aerobic fitness in middle-aged healthy Caucasians: the Medical Research Council Ely Study. Diabetes Care. 2005; 28:1195-200. CrossRef

20. Ford ES, Kohl HW 3rd, Mokdad AH, Ajani UA. Sedentary behavior, physical activity, and the metabolic syndrome among U.S. adults. Obes Res. 2005;13:608-14. CrossRef

21. Ilanne-Parikka P, Eriksson JG, Lindström J, et al. Effect of lifestyle intervention on the occurrence of metabolic syndrome and its components in the Finnish Diabetes Prevention Study. Diabetes Care. 2008;31:805-7. CrossRef

22. Pasanisi F, Contaldo F, de Simone G, Mancini M. Benefits of sustained moderate weight loss in obesity. Nutr Metab Cardiovasc Dis. 2001;11:401-6.

23. Van Gaal LF, Wauters MA, De Leeuw IH. The beneficial effects of modest weight loss on cardiovascular risk factors. Int J Obes Relat Metab Disord. 1997;21 Suppl 1:S5-9.

24. Wing RR, Koeske R, Epstein LH, Nowalk MP, Gooding W, Becker D. Long-term effects of modest weight loss in type II diabetic patients. Arch Intern Med. 1987; 147:1749-53. CrossRef

25. Lakka TA, Laaksonen DE. Physical activity in prevention and treatment of the metabolic syndrome. Appl Physiol Nutr Metab. 2007;32:76-88. $\underline{\text { CrossRef }}$

26. Hagobian TA, Phelan S. Lifestyle interventions to reduce obesity and diabetes. Am J Lifestyle Med. 2013; 7:84-98. CrossRef

27. Wang YC, McPherson K, Marsh T, Gortmaker SL, Brown M. Health and economic burden of the projected obesity trends in the USA and the UK. Lancet. 2011;378:815-25. CrossRef

28. U.S. Preventive Services Task Force. The Guide to Clinical Preventive Services: Recommendations of the U.S. Preventive Services Task Force. Rockville (MD): Agency for Healthcare Research and Quality, 2014.

(C) 2015 Aurora Health Care, Inc. 